\title{
Estimated cumulative radiation dose from PET/CT in children with malignancies: reply to Gelfand et al
}

\author{
Soni C. Chawla • M. Ines Boechat • \\ Michael McNitt-Gray
}

Received: 29 July 2010 / Accepted: 29 July 2010 / Published online: 13 August 2010

(C) The Author(s) 2010. This article is published with open access at Springerlink.com

Sir,

We highly appreciate the comments of Dr. Michael Gelfand and his colleagues [1] regarding our article [2]. We agree that when appropriate administered activities of FDG and appropriate $\mathrm{PET} / \mathrm{CT}$ protocols are used, the effective dose attributable to the addition of PET/CT to the previously required CT imaging can be much less than the $24.8 \mathrm{mSv}$ stated in our study. In the discussion portion of our manuscript, we specifically pointed out that, while our original CT protocols were adjusted for patient size, we have instituted even more aggressive dose reduction protocols (as shown in Table 3 in our article [2]) that involve reducing $\mathrm{kVp}$ as well as the use of tube current modulation (a function that was not available on the original PET/CT scanner used in this study but is now available on the systems in our current clinical practice).

We also described one key aspect of our practice, that the $\mathrm{CT}$ portion of the exam is used for diagnosis and not

S. C. Chawla $(\bowtie)$

Department of Radiology, Olive View-UCLA Medical Center, 14445 Olive View Drive, 2 D115,

Sylmar, CA 91342, USA

e-mail: chawlasoni@gmail.com

\section{I. Boechat}

Departments of Radiology and Pediatrics, David Geffen School of Medicine at UCLA, Los Angeles, CA, USA

\section{McNitt-Gray}

Department of Radiology,

David Geffen School of Medicine at UCLA,

Los Angeles, CA, USA just for PET attenuation correction. This aspect itself has a significant impact on the radiation dose delivered to the patient. To obtain diagnostic-quality $\mathrm{CT}$ images requires more radiation dose than do images that are only used for attenuation correction. However, our radiologists believe that the information obtained is vital to patient management and so it is our practice to perform these scans at levels consistent with our diagnostic protocols.

Further, it should be noted that our estimates of radiation dose were done in a very detailed manner and were not based solely on scanner-reported CTDI values, which represent dose to one of two standardized phantoms (either 16- or 32-cm phantom, depending on the manufacturer), and do not reflect actual patient dose. Instead, we used previously published Monte Carlo simulation results as well as published adjustments for patient size. We believe this provides a much more accurate estimate of actual radiation dose to individual pediatric patients than conventional estimates obtained using CTDIvol and Dose Length Product (DLP) values reported at the scanner.

Finally, the point of our study was to review our existing institutional protocols, especially for pediatric patients with malignancies who undergo frequent and repeated PET/CT scanning and to look at not just the effects of an individual scan but at the cumulative impact on these patients, even for protocols that had been only somewhat tailored for children, and to evaluate their impact in terms of the radiation exposure. It should be remembered that many institutions do not have their protocols specifically adjusted for children and that many pediatric patients with malignancies are subjected to repeated studies to monitor disease status. Therefore, protocols should be designed with a balance of radiation exposure and benefit in mind, and both CT and PET/CT studies should be performed 
with specific pediatric guidelines, thus reducing the overall radiation dose to this patient population.

Open Access This article is distributed under the terms of the Creative Commons Attribution Noncommercial License which permits any noncommercial use, distribution, and reproduction in any medium, provided the original author(s) and source are credited.

\section{References}

1. Gelfand MJ, Sharp S, Treves ST et al (2010) Estimated cumulative radiation dose from $\mathrm{PET} / \mathrm{CT}$ in children with malignancies. Pediatr Radiol. doi:10.1007/s00247-010-1794-4

2. Chawla SC, Federman N, Zhang D et al (2010) Estimated cumulative radiation dose from PET/CT in children with malignancies: a 5-year retrospective review. Pediatr Radiol 40:681686 